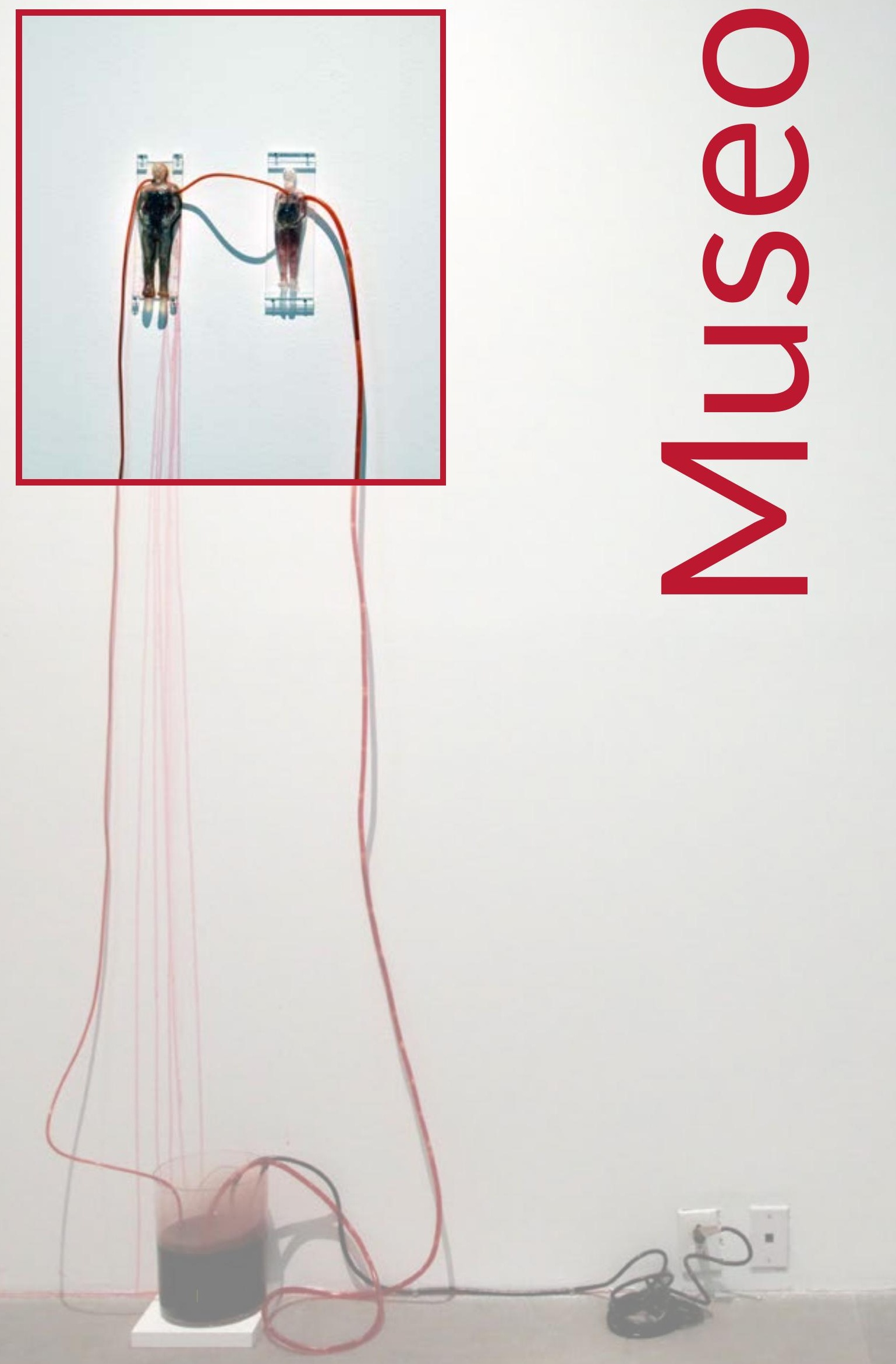




\title{
Expediente seropositivo, latencia, inminencia e inmanencia
}

\author{
Daniel Valdez Puertos
}

Artista audiovisual. Cursó la Maestría en Estudios Curatoriales. Su obra se ha presentado en diversos espacios del país, entre ellos el Centro de Cultura Digital, Cineteca Nacional, Museo

Universitario del Chopo, Centro Cultural Universitario, entre otros, así como en festivales de Latinoamerica y Europa. Fue becario del FONCA, Jóvenes creadores, 2017. Actualmente es candidato a doctor en Historia del Arte por la UNAM.

Aunque exista una reticencia del arte contemporáneo al abordaje de frente, a la intencionalidad clara y llana, al empleo del discurso denotativo, nunca dejará de ser oportuno que las prácticas de concientización sean instrumentadas por la expresión artística.

Al parecer ése es el pudor que genera en los artistas contemporáneos, pues, correr el riesgo de ser demasiado inteligibles los encasilla en un devaluado arte instrumental. Pero, ¿qué ocurre cuando una contingencia sanitaria de escala global estalla en pleno uso de las facultades sexuales? La aparición del viH en México hizo que las movilizaciones de orden artístico también tuvieran mucho que decir. Tal es lo que nos relata la exposición Expediente seropositivo, curada por Sol Henaro y Luis Matus, en el espacio del Centro de Documentación Arkheia, del Museo Universitario de Arte Contemporáneo.

Cabe resaltar que Arkehia ya ha albergado exposiciones gigantescas en términos cualitativos, pues se trata sobre todo de un lugar donde el concepto de "archivo" se expande para reclamar su propio derecho a ser visto como parte de la vida cultural en torno a las manifestaciones del arte contemporáneo del país. Es decir, no solo son piezas lo que veremos exhibidas, sino todo documento que conste de relevancia para el entendimiento a profundidad del contexto en el que se inscriben las obras de arte.

Así bien, Expediente seropositivo, con más de 120 materiales de frente al público, nos recibe de principio con una enorme mesa en la que descansan notas periodísticas, catálogos y afiches del Gran Festival Cultural 100 Artistas Contra El Sida, celebrado entre 1993 y 1995, en el Centro Cultural San Ángel -recinto hoy tristemente fuera de cualquier actividad importante del arte-.

Otros dos grandes eventos se llevaron a cabo y queda su registro en la exposición: uno en Bellas Artes, SidArte (1992), organizado por Yamina del Real y Rolando de la Rosa, quienes, frente a la incomodidad y las buenas conciencias de una sociedad mexicana renuente a escuchar del binomio sexo+enfermedad, colgaron un aparatoso condón inflable de 10 metros y un 
listón rojo, igualmente enorme, en solidaridad con los portadores de la entonces reciente epidemia. El segundo, más museístico e internacionalista, fue Sida... aún queda mucho por decir (1995), en el que participaron Francis Alÿs, Hortensia Ramírez, Héctos Blaslotosky, Leopoldo Gout, y Thomas Glassford. En esta exposición la fotografía jugó un papel de enunciación poderoso, ¿̇de qué otra forma podría hablarse mejor del SIDA sino es desde la crudeza de la imagen documental? Así, Hortensia Ramírez invitaba al visitante a tomarse una foto poniendo su cara en la imagen de un cuerpo enfermo en fase terminal, la pieza llevaba el explícito título de "Tómate una foto como no te gustaría verte". Mientras que Alÿs mostraba una fotografía de alguien caminando con una camiseta que rezaba la siguiente leyenda: "El SIDA no existe, no tendremos problema, ite lo aseguro!"

Después de este condensado breviario de exposiciones podemos apreciar piezas como las de Lorena Orozco Quiyano, Contenedores, en la que dos pequeñas figuras de silicón vacías, un hombre y una mujer, se van rellenando de supuesta sangre mediante un tubo que los conecta; o la de Hilda Campillo Si los dinosaurios los hubieran usado todavía estarían aquí que muestra una serie de empaques gigantes de condones. De esta manera, el recorrido nos va mostrando mensajes de afiches cada vez más contundentes, como la campaña de Superbarrio y la Mujer Maravilla diciendo de forma motivacional: "¡Usemos condón!", o el de "Métetelo en la cabeza", el sugestivo "Hay amores que matan", el hipergráfico felacionista "Aliméntate sanamente, usa condón”, el economicista "Bancondón, la mejor inversión para tu salud".

Un anaquel repleto del suplemento Letra S. Sida se impone en el centro museográfico de la exposición, muestra de una iniciativa periodística que tuvo a bien poner el dedo en la llaga en el momento preciso, misma que fue interrumpida por prejuicios homofóbicos de los entonces directores de El Nacional en 1994, por fortuna esta fue retomada con ímpetu por La Jornada tiempo después.

Existen tres piezas que sobresalen por su inmanente calidad artística. Una es la serie de fotografías en blanco y negro de Omar Gámez, The Dark Book, que consiste en imágenes borrosas de cuerpos en coito, en las que se evidencia la violencia consensual del acto sexual, el secreto de lo sacro revelado, positivado, el borde de los límites y el riesgo latente 


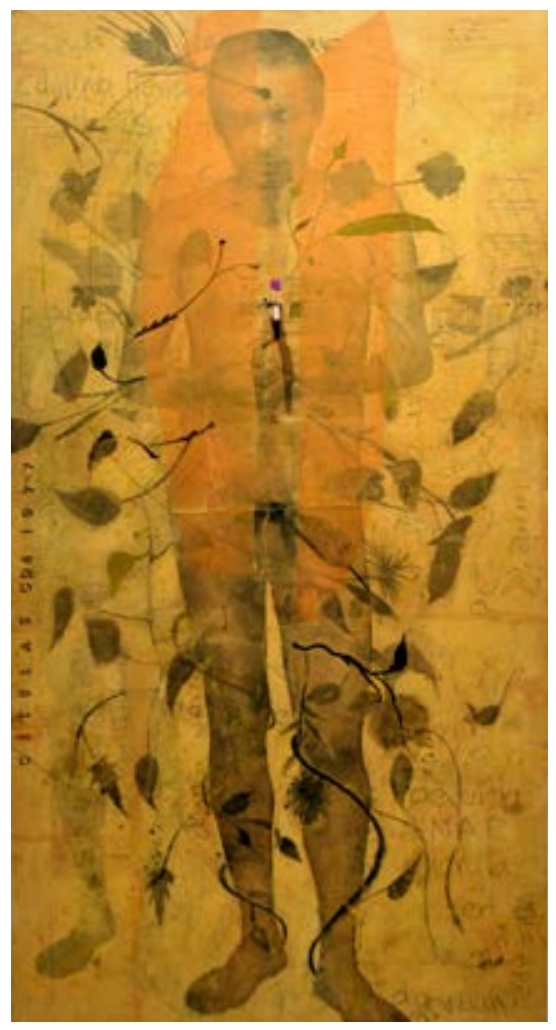

es la que adorna una esquina en una disposición poco usual en las exposiciones fotográficas.

La otra es la pieza de videoarte Lokophonía (1991), de Sergio Hernández (homónimo del artista nacido en Oaxaca, aún vivo), sobre los diferentes estadios anímicos por los que el artista transita durante la enfermedad, haciendo uso de atrevidas técnicas de video para su época, pero sobre todo nos hace preguntarnos ¿quién fue Sergio Hernández, qué otra obra hay de él? Sin duda otro de los tantos videoartistas mexicanos de los que muy probablemente nunca sabremos jamás.

Y por último quizá la pieza más interesante de todas es la de Rolando de la Rosa, Icnocuicatl Sidaids (Cantos de angustia al SIDA), un códice que habla sobre los distintos modos de transmisión, su origen y sus efectos en el cuerpo, pintado con la propia sangre del artista, empleando iconos prehispánicos, esgrimiendo la tesis que en realidad el sida no proviene de África, sino de Estados Unidos.

Hasta la fecha no deja de ser desconcertante que fuese justo después de la mayor liberación sexual de la época moderna el que haya aparecido un virus mortal cuyo target fuera por principio los homosexuales, y de paso, condujera a una modificación radical en el comportamiento sexual de una sociedad que cuestionaba la monogamia, las leyes, la política y todo régimen de control, más aún cuando la tecnología biomédica sabía instrumentalizar las infecciones para fines de dominación, no obstante, el arte y, sobre todo el arte contemporáneo, en su libertinaje de apropiación, tomó parte de una legítima causa sin miedo al medio en un momento coronado por las relaciones entrañables en tiempos de virus.

Este Expediente se abre con la intención de visibilizar, no solo un periodo del arte en México, sino todo el complejo sociológico en clave de retrospectiva para activar en el público (¿por principio juvenil?) sensibilidades antipositivas, en el sentido más filosófico del término, pues si bien en la actualidad existe un avance considerable en el tratamiento del VIH, queda claro que las respuestas por parte de la ciencia médica y las campañas de concientización aún permanecen en estado primitivo, cuando no olvidadas, y es desde la esfera del arte donde se puede llegar a las preguntas más inquietantes, sobre todo al hablar de los sectores más vulnerables de una sociedad carcomida por la incertidumbre. 

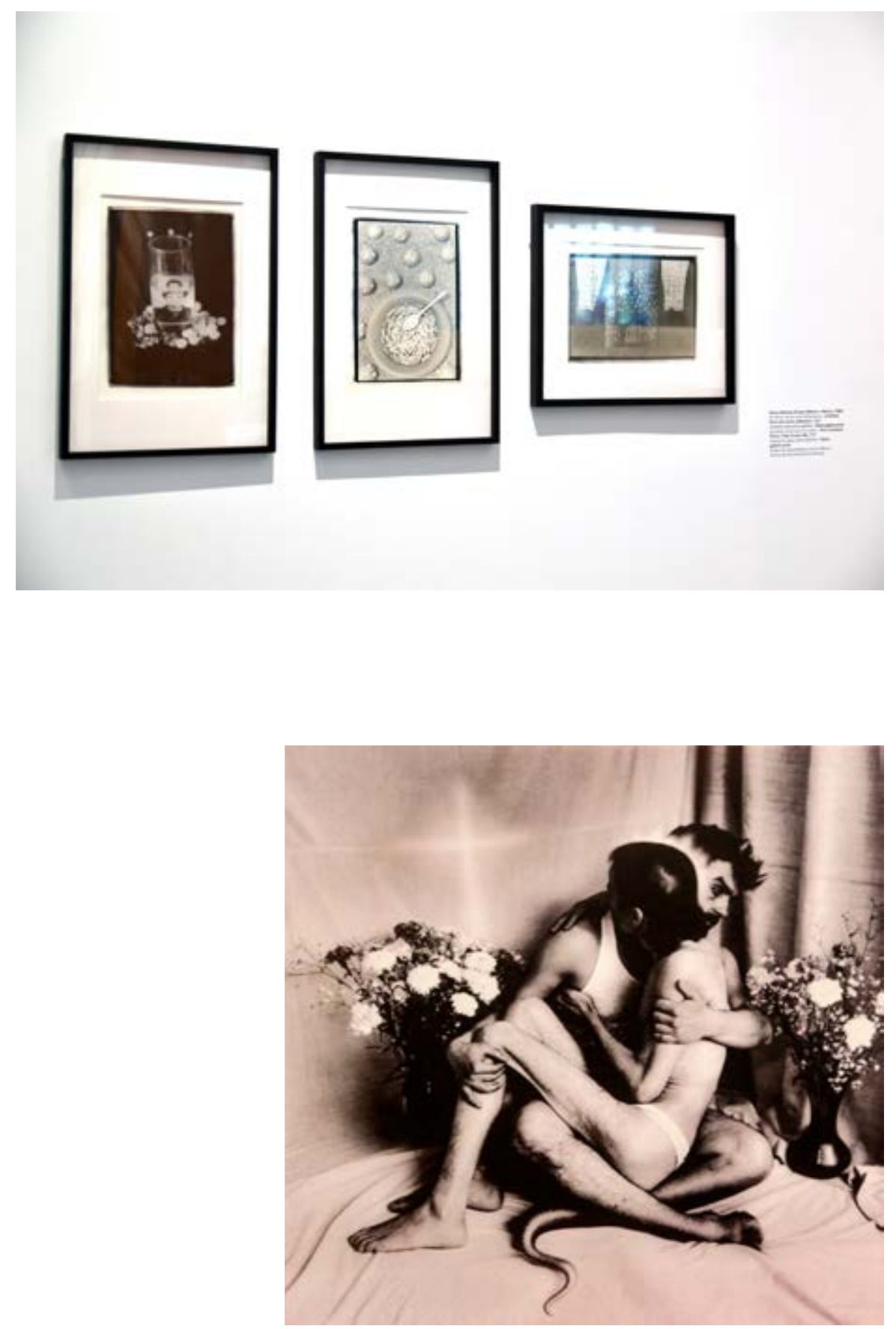

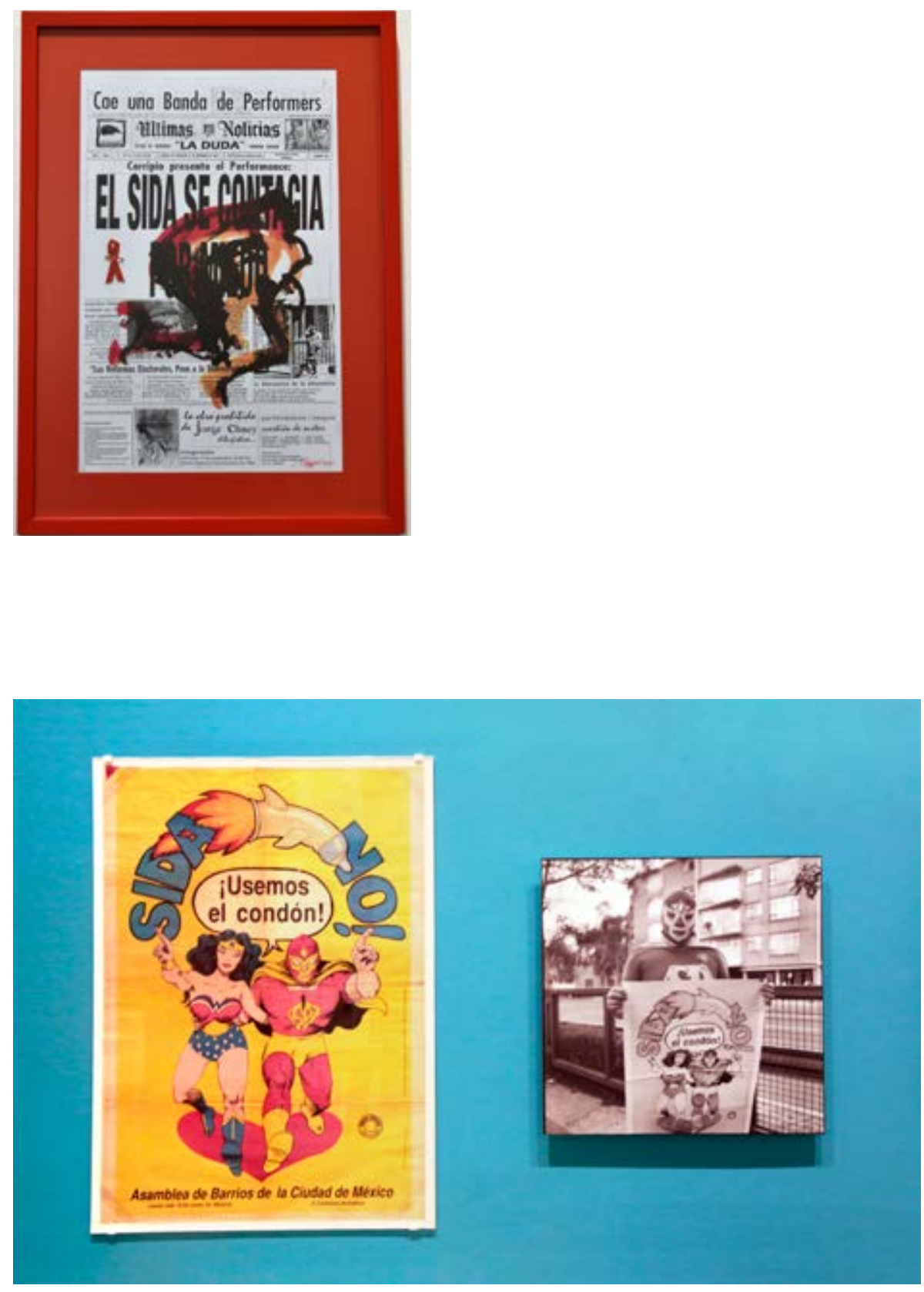

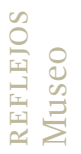



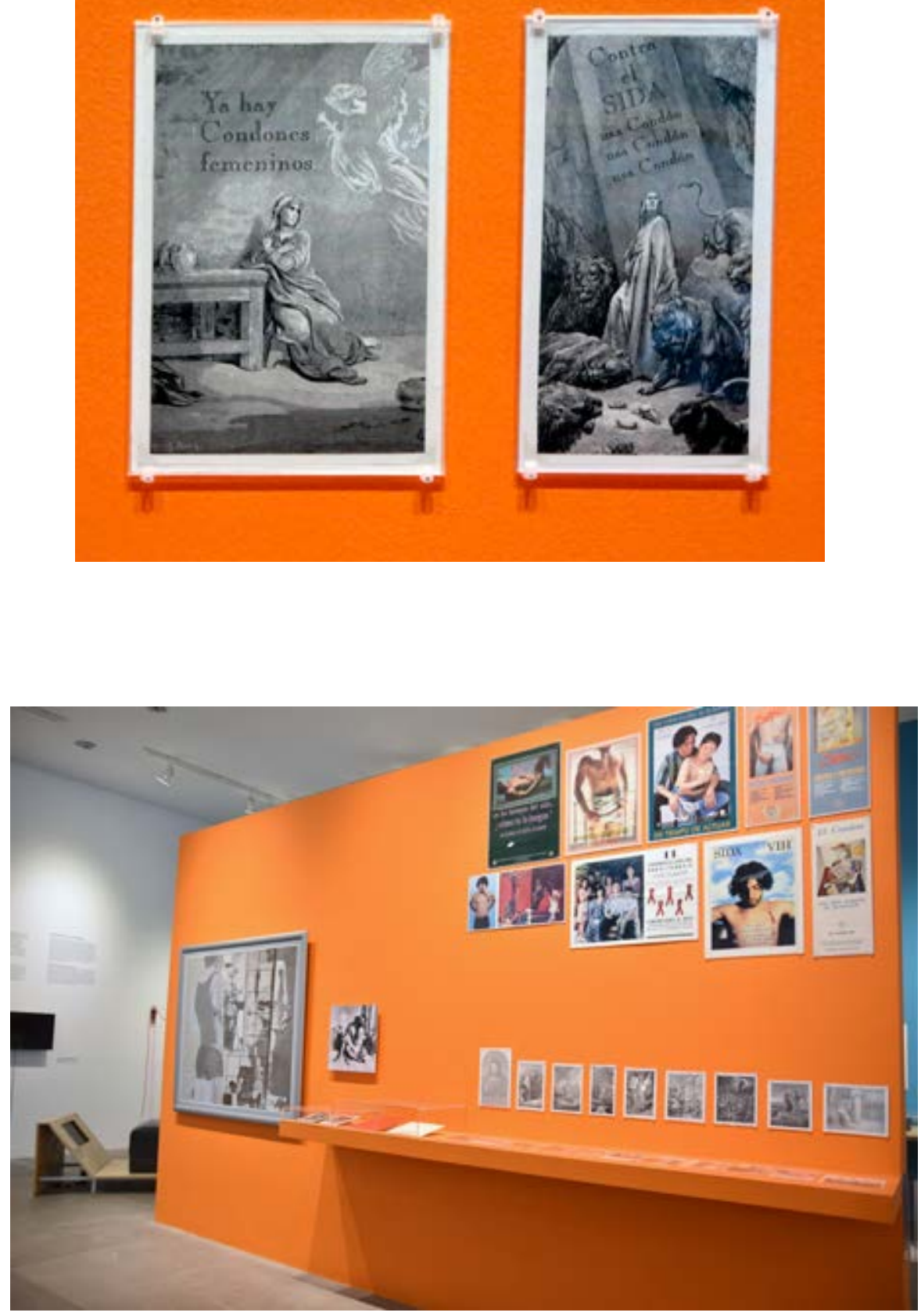

赵 